\title{
Emotional Transmission in the Classroom: Exploring the Relationship Between Teacher and Student Enjoyment
}

\author{
Anne C. Frenzel \\ University of Munich
}

\author{
Thomas Goetz \\ University of Konstanz and Thurgau University of \\ Teacher Education
}

Oliver Lüdtke

Max Planck Institute for Human Development

\author{
Reinhard Pekrun \\ University of Munich
}

\author{
Rosemary E. Sutton \\ Cleveland State University
}

\begin{abstract}
In this study, the authors examined the relationship between teacher and student enjoyment. Based on social-cognitive approaches to emotions, they hypothesized (a) that teacher enjoyment and student enjoyment within classrooms are positively linked and (b) that teacher enthusiasm mediates the relationship between teacher and student enjoyment. Self-reported enjoyment of mathematics classes was available from 1,542 students from 71 classrooms at 2 time points (Grades 7 and 8). At Time 2, mathematics teachers' reports of their enjoyment of teaching were available $(N=71)$, as well as student ratings of teacher enthusiasm. The findings were in line with theoretical expectations. Multilevel structural equation modeling showed that teacher and student enjoyment were positively related even when the authors adjusted for students' previous-class levels of mathematics enjoyment, and that the effect of teacher enjoyment on student enjoyment was mediated by teacher enthusiasm. Discussion centers on the practical implications for affective interactions in the classroom.
\end{abstract}

Keywords: enjoyment, enthusiasm, teacher, student, ML-SEM

During formal education students not only acquire knowledge and cognitive skills but also develop pleasant and unpleasant ${ }^{1}$ emotions related to learning and achievement. Despite the ubiquity of emotions in the classroom, research on emotions in educational contexts has been slow to emerge. Pleasant emotions have been particularly neglected by educational researchers (Pekrun, Goetz, Titz, \& Perry, 2002a; Schutz \& Lanehart, 2002; Schutz \& Pekrun, 2007).

Pekrun, Goetz, Titz, and Perry (2002b) argued that pleasant emotions such as students' enjoyment are worthy of investigation because they foster problem solving, protect health by promoting resiliency, create attachments to significant others, lay the ground-

Anne C. Frenzel and Reinhard Pekrun, Department of Psychology, University of Munich, Munich, Germany; Thomas Goetz, Department of Psychology, University of Konstanz, Konstanz, Germany, and Thurgau University of Teacher Education, Thurgau, Switzerland; Oliver Lüdtke, Center for Educational Research, Max Planck Institute for Human Development, Berlin, Germany; Rosemary E. Sutton, Department of Curriculum \& Foundations, College of Education and Human Services, Cleveland State University.

This research was supported by German Research Foundation Grants PE 320/11-4 and PE 320/11-5 awarded to Reinhard Pekrun.

Correspondence concerning this article should be addressed to Anne C. Frenzel, Department of Psychology, University of Munich, Leopoldstrasse 13, D-80802 Munich, Germany. E-mail: frenzel@psy.lmu.de work for individual self-regulation, and guide the behavior of groups (see also Fredrickson, 2001). Indeed, empirical studies confirm that pleasant emotions are positively related with learningrelated motivation, self-regulatory efforts, activation of cognitive resources, and performance (Ashby, Isen, \& Turken, 1999; Pekrun, 2006; Pekrun et al., 2002a). In addition, pleasant emotions toward learning and achievement form the basis of interest (Schiefele, 1991) and the willingness to reengage in academic contents over time (Hidi \& Renninger, 2006). This implies that pleasant emotions are crucial in today's knowledge-based society, which requires life-long learning. Thus, a desirable goal of teaching is to enhance students' pleasant achievement emotions.

Moreover, the emotions experienced by teachers deserve attention by researchers, administrators, and policy makers as well, particularly in light of teachers' high attrition and early retirement rates in countries around the world (e.g., Ingersoll, 2002). Although a number of studies have identified unpleasant affective states such as anger, anxiety, and burnout as core factors influencing teachers' decision to drop out of their profession (e.g., Hughes,

\footnotetext{
${ }^{1}$ In research on emotions, the terms positive and negative often are used to describe the valence of emotions (e.g., Watson, Clark, \& Tellegen, 1988). We used the terms pleasant and unpleasant since they more clearly refer to the contents of the emotional experience and do not convey any connotations regarding positive versus negative functions or effects of emotions.
} 
2001), the empirical evidence regarding pleasant teacher emotions is strikingly sparse. What does exist stems mostly from qualitative studies that indicated that teaching can be infused with pleasant emotions (Hargreaves, 1998, 2000; Sutton \& Wheatley, 2003). For example, 24 out of 30 middle school teachers interviewed about their emotions in the classroom spontaneously talked about their joy, and all of the teachers agreed that joy was relevant to their everyday work (Sutton, 2000). In addition, teachers believe that showing pleasant emotions in the classroom makes them more effective (Sutton, 2004; Witcher, Onwuegbuzie, \& Minor, 2001). Indeed, pleasant emotions may fuel teachers' efforts in pursuing in-service training opportunities, reading subject- or teachingrelated books, or planning and preparing lessons thoroughly, thus likely enhancing the quality of their teaching (Klusmann, Kunter, Trautwein, Lüdtke, \& Baumert, 2008; Kunter et al., 2008).

The present study focuses on one important pleasant emotion, namely enjoyment. We empirically test the assumption that teachers' enjoyment and students' enjoyment are positively linked due to the ongoing social interaction between teachers and students in the classroom. To test our assumption, we took a value-added approach, a technique often applied in teaching effectiveness studies (Seidel \& Shavelson, 2007; Wayne \& Youngs, 2003). In this approach, concurrent relationships between teacher characteristics and student outcomes are explored while controlling for important student prerequisites such as prior knowledge. Specifically, in the present study we examined the relationship between teacher and student enjoyment while controlling for students' enjoyment in the previous school year.

We further propose that one important mechanism mediating the transmission of enjoyment from teachers to students is teachers' enthusiasm during classroom instruction. In contrast to enjoyment as an internal experience, enthusiasm (also called teacher expressiveness or teacher immediacy; see Babab, 2007, for a review) focuses on teacher behaviors. These behaviors include gestures, varied intonation, frequent eye contact, varied emotive facial expressions, movement while lecturing, and use of humor and lively examples (Collins, 1978; Gage \& Berliner, 1998; Murray, 1983; Rosenshine, 1970). Following these earlier works in instructional research, we conceptualized teacher enthusiasm as a specific-seemingly effective-mode of instruction (Gage \& Berliner, 1998; Shuell, 2001). We argued that a teacher's individual emotional experience during teaching should translate into the degree of enthusiasm expressed in teaching style, which in turn should influence students' experiences of enjoyment while being instructed.

\section{Emotional Transmission in the Classroom}

\section{Transmission of Enjoyment and Values}

Findings from interview studies with teachers provide evidence that instructors' emotions can affect learners' emotions and behaviors. For example, in an interview about emotions and teaching, one middle school teacher said,

Teaching ... is almost scary ... because I've come to realize that my emotions ... can really dictate the mood of the class and almost how the kids are going to be that day. ... If I'm in a good mood, it can be a real positive class. ${ }^{2}$
Social-cognitive learning theories (Bandura, 1977; Pekrun, 2000) and social construction approaches (Wild, Enzle, \& Hawkins, 1992; Wild, Enzle, Nix, \& Deci, 1997) provide a theoretical framework for how the transmission of emotions from teachers to students may be initiated. Students can learn that a topic or learning task is valuable by teachers' comments, as well as by observing their teacher's enjoyment of the topic or learning task. High task values acquired though such "value induction" (Pekrun, 2000, p. 157) may in turn have positive effects on students' own enjoyment of learning. Brophy (2004, p. 266) alluded to this process as "appreciation-oriented modeling," suggesting that the teacher communicates the enjoyment involved in savoring the experience and aesthetic satisfaction of learning tasks.

One specific process explaining value induction has been suggested by Wild et al. (1992, 1997). In their model of constructive social perception, these authors argued that even if interpersonal targets do not openly display enjoyment during an action, small and implicit hints about their motivational orientation can elicit social perceivers' expectations about enjoyment of the action. In a series of experiments by Wild et al. (1992, 1997), participants were taught a skill by either seemingly extrinsically motivated teachers (paid condition) or seemingly intrinsically motivated teachers (volunteer condition). Although participants in both conditions had received identical lessons and learned to the same criterion level, participants in the group taught by seemingly extrinsically motivated teachers reported lower interest and less task enjoyment. This suggests that students' experiences of their teachers as being intrinsically versus extrinsically motivated may lead to varying levels of enjoyment of the lessons.

\section{Teacher Enthusiasm as a Mediating Variable}

Based on the assumption that social perception underlies effects of emotional transmission processes between social interaction partners, we proposed that teacher enthusiasm functions as a mediator of the relationship between teacher and student enjoyment. This assumption is based on the above-mentioned distinction between teachers' subjective enjoyment during teaching (affective experience) and teachers' expressed enthusiasm during teaching (behavioral aspect). It is plausible that teachers' experience of enjoyment translates into enthusiasm during teaching. Specifically, the behaviors associated with expressions of enjoyment, such as smiles and widened eyes (Ekman, 1982; Frijda, 1986), high and variable pitch, and higher speaking speed (e.g., Scherer, 1986), are those behaviors associated with an enthusiastic teaching style (Collins, 1978; Patrick, Hisley, Kempler, \& College, 2000). We posit that teacher enjoyment must be made visible and expressed as an enthusiastic teaching style in order for it to influence student enjoyment. In other words, a teacher's own experienced enjoyment will positively affect student enjoyment to the extent that teacher enjoyment translates into enthusiasm during teaching.

Empirical evidence supports the notion that teacher enthusiasm in turn is positively related to both students' motivation and their evaluative reaction to school classes. In their seminal overview of

\footnotetext{
2 This previously unpublished quote was obtained from an interview study with 30 teachers conducted by Rosemary E. Sutton. Details about the sample and methodology are reported in Sutton (2004).
} 
studies on effective teaching, Brophy and Good (1986) identified teacher enthusiasm as one of the core teacher qualities positively affecting motivational (more so than cognitive) outcomes. Studies experimentally manipulating teacher enthusiasm also showed positive effects on student motivation (Brigham, Scruggs, \& Mastropieri, 1992; McKinney, Robertson, Gilmore, Ford, \& Larkins, 1984; Patrick et al., 2000). In addition, two meta-analyses in secondary education (Harris \& Rosenthal, 2005; Witt, Wheeless, \& Allen, 2004) reported positive relationships between studentreported instructor enthusiasm and students' evaluative reaction toward the class $(r \mathrm{~s} \geq .40)$. However, there is a lack of studies examining relationships between teacher enthusiasm and students' discrete emotions, such as enjoyment of class.

\section{Methodological Considerations}

The extant research addressing affective interaction in the classroom comprises both laboratory and field studies, which both seem to have clear methodological limitations. In laboratory studies, teacher enthusiasm is experimentally manipulated, and effects on students' motivation are assessed (e.g., Brigham et al., 1992; McKinney et al., 1984; Patrick et al., 2000, Study 2). These studies may lack ecological validity as the learning situations in these studies usually are short term, learning is voluntary, and teachers may display unrealistic levels of enthusiasm, compared to day-today classroom learning (see also Babab, 2007). Field-based studies relate students' perceptions of their teachers' attitudes and enthusiasm during teaching to students' self-reported motivation (Christophel, 1990; Patrick et al., 2000, Study 1; Pribyl, Sakamoto, \& Keaten, 2004). In these studies, based solely on student reports, correlations between teacher attitudes as perceived by students and students' self-reported affect may be overestimated due to common method biases (Podsakoff, MacKenzie, Lee, \& Podsakoff, 2003). We know of no study addressing affective processes in teacher-student interaction that, in addition to student reports, also incorporated teachers' own reports regarding their emotional experiences during teaching.

We designed the present research to overcome these methodological problems and to provide more robust evidence on emotional transmission in teacher-student interactions. First, this study was field based and explored emotions in existing, everyday classrooms. Second, this study incorporated different perceptual perspectives, asking teachers about their enjoyment while teaching a particular class and asking students about their enjoyment during instruction. In addition, students were asked to rate how enthusiastic they perceived their teachers to be. Enthusiasm as a behavioral variable can directly be observed by students. Therefore, class-aggregated student ratings can be considered most suitable to assess this variable. Several studies have documented the value of student reports, aggregated to class means, to assess instructional variables (Aleamoni, 1999; Clausen, 2002; De Jong \& Westerhof, 2001; Trautwein, Lüdtke, Schnyder, \& Niggli, 2006).

In line with earlier research on emotions in the classroom, we used a traitlike approach to assess students' and teachers' emotions by asking students how they "generally feel in this class" and by asking teachers how they "generally feel when teaching this particular group of students." This corresponds with an interactionist view of emotional traits, which assumes that emotions remain relatively stable across time but only across sufficiently similar situations (e.g., Johnson, 1999; Shoda, 1999; Tett \& Guterman, 2000), implying that teachers' and students emotional traits are considered context specific. Context specificity of students' emotions in terms of domain specificity has been well-documented in recent research (e.g., Goetz, Frenzel, Pekrun, \& Hall, 2006; Goetz, Frenzel, Pekrun, Hall, \& Lüdtke, 2007)—students feel quite different in their mathematics classes than in their English classes, for example. The present study focuses on one single important subject domain, namely mathematics.

\section{The Present Research}

In sum, the findings of qualitative interview studies suggest that there are positive links between teacher enjoyment and student enjoyment in the classroom. To date, however, there is a lack of robust, quantitative evidence about this relationship. In addition, regarding emotional transmission from teachers to students, it seems plausible that teachers' enjoyment during teaching translates into an enthusiastic teaching style (Ekman, 1982; Frijda, 1986; Scherer, 1986), and there is evidence that teacher enthusiasm positively influences students' evaluative reactions to courses (Harris \& Rosenthal, 2005; Witt et al., 2004). However, there is a lack of empirical evidence documenting relationships between teachers' enjoyment and enthusiasm, and between teacher enthusiasm and students' discrete emotions, such as enjoyment.

Addressing these research deficits, we aimed in the present study at exploring the relationships between teacher enjoyment, teacher enthusiasm, and student enjoyment in mathematics. To this end we used data from a longitudinal field study that included self-reports from both teachers and students. In analyzing the data, we took the multilevel data structure into account, with students (Level 1) nested within classrooms and teachers (Level 2). Succinctly stated, we hypothesized (a) that teacher enjoyment and student enjoyment would be positively linked, even when controlling for prior levels of student enjoyment in the previous school year and (b) that the relationship between teacher enjoyment and student enjoyment would be mediated by teachers' enthusiasm.

\section{Method}

\section{Design and Samples}

The longitudinal design of the present study included assessments of students' mathematics enjoyment at two time points (Grade 7 and Grade 8) and of teacher enjoyment and studentperceived teacher enthusiasm at the second time point (Grade 8). The measures were each administered at the end of the academic school year. The study design thus made it possible to analyze the development of student enjoyment from the end of Grade 7 to the end of Grade 8 after a full year of classroom interaction. It also allowed us to explore how teacher and student enjoyment were related at the end of Grade 8, while controlling for the level of student enjoyment in the previous school year. In other words, we explored whether teacher enjoyment in Grade 8 was related to changes in student enjoyment from Grade 7 to Grade 8 .

The student sample consisted of 1,763 eighth-grade students ( $52 \%$ female, mean age $=14.77$ years, $S D=0.58$ years) from 71 classrooms in the state of Bavaria, Germany. The sample comprised a wide range of socioeconomic backgrounds, including both 
rural and urban areas and students from all three schools tracks of the German state school system. Complete classes were sampled. The mean number of participating students per class was 24.8 (minimum $=11$, maximum $=35, S D=4.8$ ). Written parental consent was required to allow students to participate. Students' answers were kept strictly confidential.

Because the study is embedded in a longitudinal investigation (Project for the Analysis of Learning and Achievement in Mathematics; Pekrun et al., 2007), student data were also available from the previous school year (Grade 7). In the German state school system, students typically stay together as a group across Grades 7 and 8. Nevertheless, due to several factors (e.g., illness, relocation), not all of the students who participated in Grade 8 (Time 2) had also participated in Grade 7 (Time $1 ; n_{\text {present in Grade } 7}=$ 1,542). However, on average $87.5 \%$ of the students in the Grade 8 classes were also present in Grade 7 (minimum $=34 \%$, maximum $=100 \%$ ). Therefore, it can be assumed that Grade 7 level of enjoyment in these classes could be estimated on the basis of the reduced sample size. In addition, attrition at Time 1 relative to Time 2 was not related to background characteristics or any of the variables included in the analysis (neither gender proportions nor means and standard deviations of the relevant dependent variables significantly differed between the full and the reduced sample in Grade 8).

The teacher sample consisted of the 71 teachers ( 21 women and 50 men) who taught mathematics in the participating Grade 8 classes. Their mean age was 45.0 years $(S D=11.8)$ with an average of 16.7 years of teaching experience $(S D=12.3)$. The age distribution, teaching experience, and percentage of women in the teacher sample were representative for the population of Bavarian mathematics teachers (Bavarian State Ministry of Education, 2005). In the Bavarian school system, teachers usually do not teach the same groups of students in subsequent years. Therefore, most of the Grade 8 classes in this study presumably had been taught by a different mathematics teacher in Grade 7.

\section{Measures}

Teacher enjoyment. Due to the lack of scales measuring teacher enjoyment, we developed a teacher enjoyment scale for the present study. Items were formulated such that they referred to the group of students participating in the study (5 items; "I really enjoy teaching mathematics in this class," "I look forward to lessons in this class," "My teaching in this class is so enjoyable that I like lecturing and preparing my lessons for this class," "When teaching this class, I am good humored," and "Teaching in this class gives me many reasons to be pleased"). Items were answered on a 5-point Likert scale ranging from 1 (strongly disagree) to 5 (strongly agree). Internal consistency of this scale was high (Cronbach's $\alpha=.90)$.

Student enjoyment. We used the class-related enjoyment items of the Achievement Emotions Questionnaire-Mathematics (Pekrun, Goetz, \& Frenzel, 2005) to assess students' enjoyment during mathematics classes. Instructions ask students to indicate how they typically feel about attending class (4 items; e.g., "I look forward to my mathematics class," "I enjoy my mathematics class"). Items were answered on a 5-point Likert scale ranging from 1 (strongly disagree) to 5 (strongly agree). The scale was highly internally consistent (Cronbach's $\alpha=.89$ and .88 in Grades 7 and 8, respectively).

Student-perceived teacher enthusiasm. To assess students' perception of teacher enthusiasm, we used a four-item scale ("Our mathematics teacher teaches with enthusiasm," "Our mathematics teacher is humorous during teaching," "Our mathematics teacher tries to get students excited about the subject of mathematics," and "Our mathematics teacher really seems to take pleasure in teaching"). Item formulations were based on existing scales from teaching evaluation studies (Jackson et al., 1999; Marsh, 1982). Items were answered on a 5-point Likert scale ranging from 1 (strongly disagree) to 5 (strongly agree). Internal consistency was high (Cronbach's $\alpha=.85$ ).

Assessing the reliability of student measures at the class level. To determine whether aggregated individual-level ratings of student enjoyment and perceived enthusiasm were reliable indicators of the respective class-level constructs, we used the intraclass correlations (ICC) Type 1 and 2 (Bliese, 2000; Snijders \& Bosker, 1999). ICCs are based on a one-way analysis of variance with random effects; in the present case, student enjoyment and perceived enthusiasm are the dependent variables, and class membership is the independent variable.

The ICC(1) can be interpreted in two ways: It is the correlation between the scores of two randomly selected individuals in one randomly selected class and it is also the fraction of total variance due to class membership (Snijders \& Bosker, 1999). The ICC(1) thus renders an estimate of the within-class homogeneity of aggregated group-level constructs. Values of .05 and above for ICC(1) can be regarded as support that there are adequate grouplevel properties of a variable to warrant aggregation (e.g., Gavin \& Hofmann, 2002). Whereas the ICC(1) can be interpreted as the reliability of an individual student's rating as an indicator of a class-level variable, the $\mathrm{ICC}(2)$ provides an estimate of the reliability of the class-mean rating (Lüdtke, Trautwein, Kunter, \& Baumert, 2006). It is estimated by applying the Spearman-Brown formula to the ICC(1), using the average number of students per class as test length (Bliese, 2000; Snijders \& Bosker, 1999). ICC(2) values of approximately .70 are considered to indicate sufficient reliability of class-level aggregated scores (Bliese, 2000; LeBreton \& Senter, 2008).

The ICC(1) for enjoyment was .09 in Grade 7 and .08 in Grade 8 , implying that there was quite some within-class homogeneity in the enjoyment of mathematics classes. The ICC(2) for enjoyment was .69 in Grade 7 and .68 in Grade 8, indicating that the reliability of the class-level assessment of students' enjoyment was acceptable.

The ICC(1) for student-perceived teacher enthusiasm was .30, indicating that there was considerable within-class homogeneity in how students perceived their teachers. The ICC(2) was .91, indicating a high reliability of student ratings aggregated at the class level. In addition to reliability, we also assessed the absolute agreement of students within a class (i.e., the extent to which students within a class assigned the same ratings to their teacher). Aggregating individual student ratings to assess group-level constructs (such as teacher behavior) is acceptable only if there is sufficient interrater agreement within groups (Bliese, 2000; Lüdtke et al., 2006). We used the average deviation index $A D_{M}$ that assesses the deviations of students' ratings from the class mean and that can be interpreted in terms of the original rating metric 
(Burke, Finkelstein, \& Dusig, 1999). For instance, an $A D_{M}$ of 1 means that on average the students in a class deviate from the class mean by one unit of the rating scale. The average $A D_{M}$ across classes was .68. For 5-point Likert scales, Burke et al. (1999) regarded an $A D_{M}$ of less than .83 as evidence for sufficient interrater agreement. In our data, $83 \%$ of the classes had an $A D_{M}$ below that value; the remaining 12 classes only marginally exceeded this value (maximum $A D_{M}=1.07$ ). Sufficient interrater agreement thus existed within the participating classes, justifying the assessment of teacher enthusiasm by means of classaggregated student ratings.

\section{Strategy of Data Analysis}

The data from the participating 1,763 students were nested within data from 71 classrooms and corresponding teachers. Therefore, testing our assumptions required a multilevel analysis approach. We used multilevel structural equation modeling (ML-SEM) as it offers considerable advances over conventional multilevel modeling procedures by allowing integration of multiple outcome variables, estimation of both direct and indirect effects, and a consideration of measurement error at both levels of analysis by using multiple indicators (see Mehta \& Neale, 2005).

We used Mplus (Muthén \& Muthén, 1998-2006) to construct our multilevel structural equation models. Instead of viewing the hierarchical data structure (students nested within classes) as a disturbance, the ML-SEM approach treats the different levels as objects of analysis. In the present study with students nested within classrooms, the observed interindividual differences comprise variance stemming from two sources: variability at the level of individual students and variability at the level of classrooms. In ML-SEM, effects at the individual level (effects within classes) and effects at the class level (effects between classes) are estimated simultaneously. Variables measured at the within-class level can be modeled as latent constructs both at the within-class and at the between-classes level, and can thus also be linked to other variables measured at the between-classes level.

Due to the longitudinal design of the study and some amount of item nonresponse within each assessment, a certain proportion of missing data was inevitable. Rather than applying listwise deletion, we applied the full information maximum likelihood method (Schafer \& Graham, 2002). This approach has the important advantage of providing results that better represent the entire sample, rather than just the subsample of students who have no missing data. In addition, this method provides appropriate tests of statistical significance that take the amount of missing data into account. The full information maximum likelihood method also allows an integration of estimating parameters and dealing with missing data within one single step and provides appropriate parameter estimates and standard errors (e.g., Allison, 2001).

As in any structural equation approach, ML-SEM provides fit indices to judge the goodness of fit between the empirical data and the model-implied data structures. In order to assess goodness of fit, we used the comparative fit index (CFI) and the Tucker-Lewis index (TLI). The CFI and the TLI are relative fit indices indicating the goodness of fit of a model compared to a baseline model assuming that all constructs involved are unrelated (see, e.g., Byrne, 1998). In addition, we inspected the root-mean-square error of approximation (RMSEA), as well as the standardized root- mean-square residual (SRMR), which are absolute fit indices based on the discrepancy between model-implied and empirically obtained covariance matrices (Byrne, 1998). Mplus calculates the SRMR separately for the within-class $\left(\mathrm{SRMR}_{\text {within }}\right)$ and betweenclasses $\left(\mathrm{SRMR}_{\text {between }}\right)$ matrices. Applying the rules of thumb for evaluating fit suggested by $\mathrm{Hu}$ and Bentler (1999), we assumed that values greater than or equal to .95 for CFI and TLI as well as lesser than or equal to .06 for the RMSEA and the SRMR indicate a good model fit, and that values as low as .90 for CFI and TLI and as high as .08 for the RMSEA and .10 for the SRMR would indicate a moderate fit.

In accordance with our hypotheses, we performed the ML-SEM analyses in three steps. In Step 1, the links between student enjoyment and teacher enjoyment in Grade 8 were modeled. In Step 2, student enjoyment in Grade 7 was entered as a covariate. In Step 3, student-perceived teacher enthusiasm in Grade 8 was entered into the model as a mediator for the relationship between teacher and student enjoyment in Grade 8. Mediation was assessed by inspecting the size and statistical significance of the direct effect of teacher enjoyment on student enjoyment after the introduction of the mediator, and by testing the statistical significance of the indirect effect mediated by teacher enthusiasm (Kenny, Kashy, \& Bolger, 1998; MacKinnon, Fairchild, \& Fritz, 2007; Muthén \& Muthén, 1998-2006).

\section{Results}

\section{Preliminary Analysis}

Table 1 shows the descriptive statistics for the study variables. Students' enjoyment of mathematics classes generally decreased from Grade 7 to Grade 8 . This decrease was statistically significant (repeated measures $t$ test, $t[1,541]=2.64, p<.01$ ), but it was very small in terms of effect size (Cohen's $d=.06$ ).

We next inspected the attenuated (i.e., manifest) Pearson product-moment correlations between the study variables both at the individual level and at the class level. Table 2 presents these correlations, which were all positive and significant $(p s<.01)$. It is important to note that the coefficients at the individual level are based on the total student sample, disregarding the nested structure of the data. Of major interest for the present research question was the relationship between teacher enjoyment and average student

Table 1

Descriptive Statistics of Teacher Enjoyment, Student Enjoyment, and Perceived Teacher Enthusiasm

\begin{tabular}{lccc}
\hline \multicolumn{1}{c}{ Variable } & $N^{\mathrm{a}}$ & $M$ & $S D$ \\
\hline Class level & & & \\
$\quad$ Teacher enjoyment Grade 8 & 71 & 3.69 & 0.68 \\
Individual level & & & \\
$\quad$ Student enjoyment Grade 7 & 1,541 & 2.59 & 0.98 \\
$\quad$ Student enjoyment Grade 8 & 1,759 & 2.52 & 0.96 \\
$\quad$ Perceived teacher enthusiasm Grade 8 & 1,725 & 3.14 & 1.03 \\
\hline
\end{tabular}

Note. Scale averages (sum of answers to items comprising a scale divided by item number) are displayed. Possible range was 1.0 to 5.0 for each scale. Observed range was 1.0 to 5.0 for each scale, except for the teacher enjoyment scale, which had an observed minimum of 1.80 .

${ }^{a}$ Varying numbers due to missing data. 
Table 2

Pearson Product-Moment Correlations Among the Study Variables

\begin{tabular}{lcccc}
\hline \multicolumn{1}{c}{ Variable } & 1 & 2 & 3 & 4 \\
\hline 1. Teacher enjoyment Grade 8 & - & .32 & .38 & .34 \\
2. Student enjoyment Grade 7 & a & - & .72 & .37 \\
3. Student enjoyment Grade 8 & a & .56 & - & .58 \\
4. Perceived teacher enthusiasm Grade 8 & a & .26 & .40 & -
\end{tabular}

Note. Correlations at the between-classes level are shown above the diagonal $(N=71)$. Correlations on the individual level are shown below the diagonal (1,508 $\leq N \leq 1,726$ due to missing data). All correlations are significant $(p<.01)$.

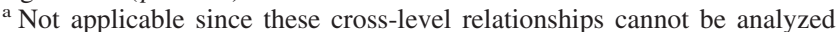
adequately by means of Pearson product-moment correlations due to the multilevel data structure.

enjoyment in Grade 8, which was $r=.38$. In addition, teacherreported enjoyment was positively linked to average perceived teacher enthusiasm in Grade $8(r=.34)$, and perceived teacher enthusiasm and student enjoyment also were positively linked $(r=$ .40 at the individual level; $r=.58$ at the class level).

These initial analyses provided preliminary evidence supporting the hypothesis that teacher enjoyment, student enjoyment, and perceived teacher enthusiasm are all positively linked. Subsequently, we performed ML-SEM analyses to account for the nested data structure and to test our specific hypotheses.

\section{ML-SEM Analysis}

In the multilevel structural equation models, items were used as indicators of the latent variables teacher enjoyment, student enjoyment, and student-perceived teacher enthusiasm. To achieve model identification, we set the first factor loadings of each latent variable to one. The variances were freely estimated, with isolated exceptions in the between-classes models (see Appendix A), where variances were initially estimated to values below zero and subsequently constrained to be zero (this is a customary and recommendable strategy as long as the size of negative variance estimates is not significantly different from zero, which was not the case with the present data set; see Hox, 2002). Appendixes A and B show the item loadings and error variances as well as correlations of all manifest variables included in the final mediation model.

Our structural equation models generally consisted of two levels, a within-class level (addressing effects at the student level within classes) and a between-classes level (addressing effects between classes), to account for the nested structure of the data. Effects at the two levels were estimated simultaneously. We first created a model in which student enjoyment in Grade 8 was modeled as a latent construct both at the within-class and at the between-classes level, and teacher enjoyment in Grade 8 was modeled at the class level. To test the assumption that teacher and student enjoyment are positively linked (Hypothesis 1), we modeled the correlation between teacher enjoyment and student enjoyment at the class level. This simple model had a very good fit $\left(\chi^{2}[28]=56, p<.01 ; \mathrm{CFI}=.99 ; \mathrm{TLI}=.99 ; \mathrm{RMSEA}=.024 ;\right.$ $\mathrm{SRMR}_{\text {between }}=.091$; and $\left.\mathrm{SRMR}_{\text {within }}=.003\right)$. The significance of the chi-square statistic can be attributed to the large sample size at the student level, to which this statistic has been shown to be overly sensitive (Marsh, Balla, \& McDonald, 1988). Applying the rule of thumb that the $\chi^{2} / d f$ ratio should be smaller than three (Ullman, 2007), the chi-square statistic can also be judged as acceptable. The latent correlation between teacher and student enjoyment in this model was .63 $(p<.01)$, clearly supporting a positive relationship between teacher and student experiences of enjoyment within classrooms.

In a next step, we added student enjoyment of mathematics in Grade 7 (i.e., previous grade) into the model, both at the withinclass and at the between-classes level. At the within-class level, the autoregression from student enjoyment in Grade 7 to Grade 8 was modeled. At the between-classes level, student enjoyment in Grade 8 was regressed on teacher enjoyment in Grade 8 and on student enjoyment in Grade 7, while the latter two were allowed to correlate. Again, the fit indices confirmed a very good fit $\left(\chi^{2}[82]=191, p<.01 ; \mathrm{CFI}=.98 ; \mathrm{TLI}=.98 ; \mathrm{RMSEA}=.028 ;\right.$ $\mathrm{SRMR}_{\text {between }}=.085$; and SRMR $\left.\mathrm{Sithin}=.015\right)$. At the within-class level, the autoregression between Grade 7 enjoyment and Grade 8 enjoyment was considerable in size $(\beta=.61, p<.01)$. At the between-classes level, student enjoyment in Grade 7 and teacher enjoyment in Grade 8 were positively correlated (latent $r=.45$, $p<.01)$. In addition, despite a relatively high stability of mathematics enjoyment at the class level with an autoregression of .70 $(p<.01)$, teacher and student enjoyment in Grade 8 were still significantly positively related with a standardized latent regression weight of $\beta=.32(p<.05)$.

In the third step, we explored the relationship between teacher and student enjoyment in more detail by testing Hypothesis 2, predicting that this relationship should be mediated by teacher enthusiasm. The corresponding model and standardized path coefficients are depicted in Figure 1. The inspected range of fit indices again indicated a very good model fit $\left(\chi^{2}[166]=311.63\right.$, $p<.01 ; \mathrm{CFI}=.99 ; \mathrm{TLI}=.98 ; \mathrm{RMSEA}=.022 ; \mathrm{SRMR}_{\text {between }}=$ .078 ; and $\mathrm{SRMR}_{\text {within }}=.018$ )

The pattern of coefficients in this model largely reflects the hypothesized relationships. At the within-class level (lower part in Figure 1), student enjoyment in Grade 8 was regressed on student enjoyment in Grade 7 and perceived teacher enthusiasm in Grade 8 , while the latter two were allowed to correlate. There was again a relatively strong autoregressive path from student enjoyment in Grade 7 on student enjoyment in Grade 8 ( $\beta=.53, p<.01)$, but perceived teacher enthusiasm had an additional positive effect of $\beta=.31(p<.01)$. Furthermore, student enjoyment in Grade 7 was positively associated with perceived teacher enthusiasm in Grade 8 $(r=.27, p<.01)$. Overall, $45.9 \%$ of the within-class variance of student enjoyment in Grade 8 was explained in this model.

At the between-classes level (upper part in Figure 1), student enjoyment in Grade 8 was regressed on student enjoyment in Grade 7 and on perceived teacher enjoyment, as well as on perceived teacher enthusiasm in Grade 8. In addition, teacher enjoyment was assumed to predict perceived teacher enthusiasm. The hypothesized mediation of the effect of teacher enjoyment on student enjoyment by teacher enthusiasm was thus modeled. Student enjoyment in Grade 7 and teacher enjoyment in Grade 8 as well as student enjoyment in Grade 7 and perceived teacher enthusiasm in Grade 8 were allowed to correlate. Results showed that student enjoyment in Grade 7 and teacher enjoyment in Grade 8 were positively correlated (latent $r=$ $.45, p<.01)$, but student enjoyment in Grade 7 was unrelated to 


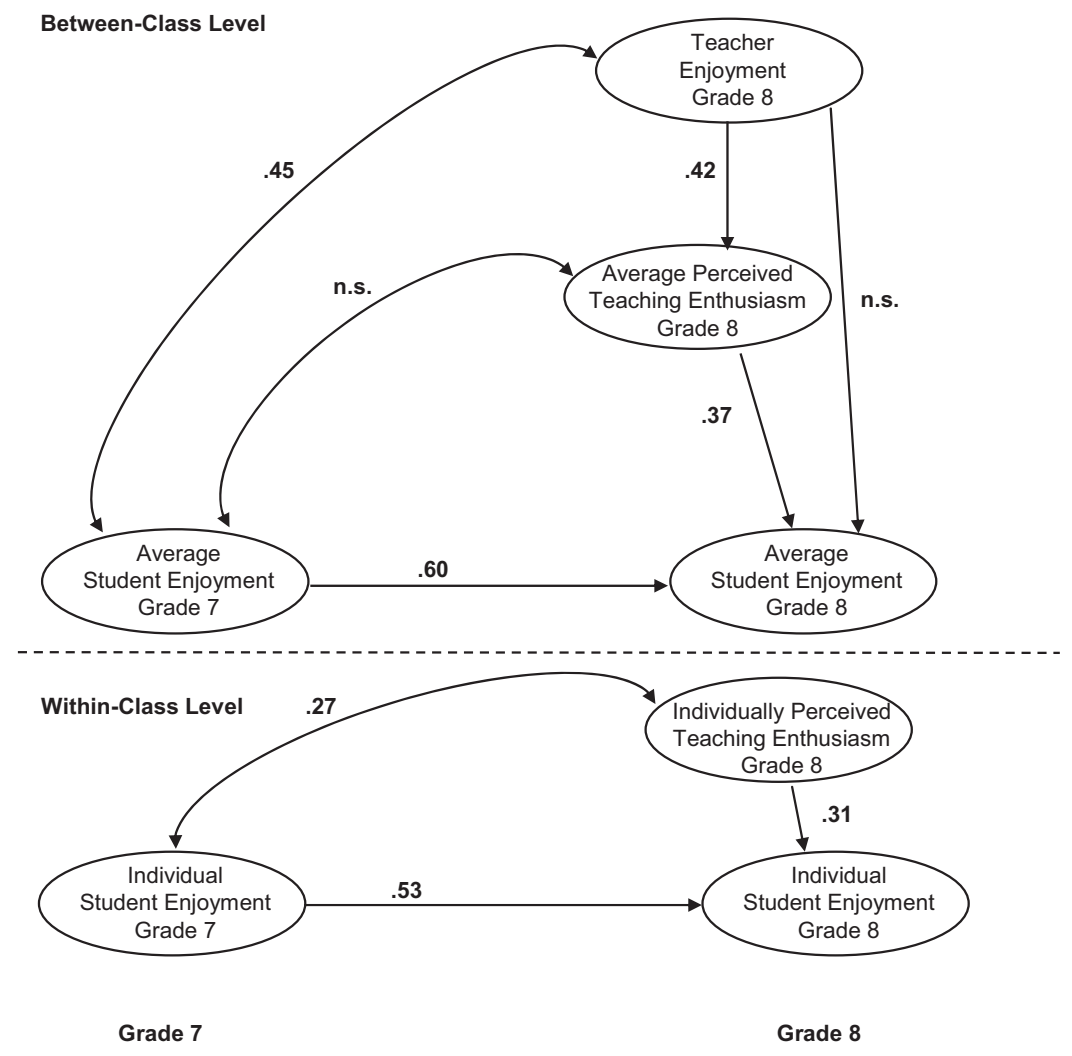

Figure 1. Multilevel structural equation model for the relationships between teacher enjoyment, student enjoyment, and teacher enthusiasm (standardized coefficients). All coefficients are significant $(p<.01)$ unless otherwise indicated.

perceived teacher enthusiasm in Grade 8. In addition, there was again a rather strong autoregressive path from student enjoyment in Grade 7 on enjoyment in Grade $8(\beta=.60, p<.01)$. Consistent with our mediation hypothesis, teacher enjoyment significantly predicted student-perceived enthusiasm during teaching $(\beta=.42, p<.01)$, which in turn significantly predicted student enjoyment $(\beta=.37, p<$ .01). The direct path from teacher enjoyment to student enjoyment was no longer statistically significant $(\beta=.22, p=.08)$, further supporting the mediation assumption. In addition, the procedure estimating indirect effects implemented in Mplus (IND command; see Muthén \& Muthén, 1998-2006) confirmed that the indirect, mediated effect of teacher enjoyment on student enjoyment was statistically significant $(p<.05)$. Overall, $89.4 \%$ of the between-classes variance of student enjoyment was explained in this model. ${ }^{3}$

\section{Discussion}

In this study, we explored the relationship between mathematics teachers' enjoyment of teaching and students' enjoyment while attending mathematics class. We proposed that both teacher enjoyment and student enjoyment deserve more attention in educational research than they have received so far because they are of critical importance for the quality of teaching and learning (Kunter et al., 2008; Pekrun et al., 2002a; Schutz \& Lanehart, 2002). We hypothesized that teachers' and students' enjoyment are positively linked because of the ongoing interaction between teachers and students in the classroom. Based on social-cognitive assumptions (Pekrun, 2000; Wild et al., 1992, 1997) implying that emotional transmission is based on socially perceivable hints about the emotional state of other persons, we further proposed a mediation mechanism for the transmission of enjoyment from teachers to students. Specifically, we predicted that the relationship between teacher enjoyment and student enjoyment would be mediated by teachers' displayed enthusiasm during teaching.

Our findings supported these hypotheses. First, enjoyment reported by mathematics teachers was positively related to students' enjoyment of mathematics classes, even when controlling for

\footnotetext{
${ }^{3}$ To test whether teachers' enthusiasm from the previous school year had effects on students' enjoyment, beyond the effects of the current teacher, we ran an additional model that also incorporated student perceptions of teacher enthusiasm in Grade 7 (these data were available in our longitudinal data set, whereas no self-report data were available from the previous-year mathematics teachers). This model had a very good fit, $\chi^{2}(44)=101\left(\mathrm{CFI}=.99 ; \mathrm{TLI}=.98 ;\right.$ RMSEA $=.027 ; \mathrm{SRMR}_{\text {within }}=$ $\left..006 ; \mathrm{SRMR}_{\text {between }}=.057\right)$. It revealed that at the between-classes level, perceived teacher enthusiasm in Grade 7 was unrelated to student enjoyment in Grade 8. In addition, the mediation remained largely unaffected upon the introduction of Grade 7 teacher enjoyment. This implies that only the current teacher is relevant in determining students' emotional experiences, whereas teachers do not seem continue to have any effects on student enjoyment in the subsequent year.
} 
student enjoyment in the previous school year. This can also be interpreted in terms of teacher enjoyment being positively related with the change in student enjoyment that occurs between Grades 7 and 8 . In addition, in line with our second hypothesis, enjoyment as reported by teachers was positively associated with student perceptions of teacher enthusiasm, and teacher enthusiasm in turn was positively linked to students' levels of enjoyment. The indirect, mediated effect of teacher enjoyment on student enjoyment was substantial and statistically significant. These findings add to the literature on teacher and student affect and provide evidence regarding potential underlying processes. Specifically, the mediation we found provides support for the view that a teacher's enjoyment during teaching has positive effects on student enjoyment via observable enthusiastic teaching behavior. Our data also imply that teachers do make a difference in terms of students' emotional experiences in the classroom and in terms of how students' experiences change across years.

\section{Enthusiasm as a Teaching Strategy}

A related intriguing question is whether the experience of enjoyment is a necessary condition for an enthusiastic teaching style or whether teachers can appear to be enthusiastic even if they are not enjoying teaching. We believe that teachers who truly enjoy teaching will assuredly teach enthusiastically-at least to some degree. The amount of expressed enthusiasm may vary because of individual differences in emotion expressiveness. Nevertheless, it may be possible for teachers to adopt an expressive, enthusiastic teaching style without actually enjoying teaching. For example, one teacher said in an interview, "Even if I am not interested, I have to pretend. I have to put up a front that I'm extremely interested in what I am doing" (Sutton, 2004, p. 379).

The costs and benefits of up-regulating positive emotional expressiveness without actually experiencing the emotion are debated. In the emotional labor approach, attempts to up-regulate pleasant emotions are believed to take effort and lead to stress and burnout (Hochschild, 1983). This approach has also been applied to teachers (e.g., Hargreaves, 2000). In contrast, psychological research on emotion regulation stresses the benefits of upregulating pleasant emotions, arguing that modifying immediate responses in the service of long-term goals can increase overall psychological functioning (Twenge \& Baumeister, 2002). In fact, reports by teachers suggest that they often regulate their immediate emotions in order to aid their long-term instructional goals (Sutton, 2004). For instance, teachers report showing enthusiasm when the topic is dry or when teaching a challenging group of children. Our data suggest that this may indeed be a useful strategy because enthusiasm seems to have positive effects on students' enjoyment.

\section{Limitations of the Study}

While this study was designed to overcome methodological problems in previous field-based and experimental studies, a number of limitations of the present study may be noted and used to suggest directions for future research. First, the classical valueadded design of teaching effectiveness research we used in the present study is limited due to the synchronous assessment of the study variables in Grade 8. While the proposed effect of teacher enjoyment on student enjoyment as mediated by teacher enthusi- asm is theoretically highly plausible and supported by the study findings, aside from effects of teacher enjoyment on student enjoyment, the reverse order of effects is also conceivable. For instance, research has shown that students' positive affect may contribute to teachers' enjoyment during teaching (e.g., Pelletier \& Vallerand, 1996; Stenlund, 1995). The ML-SEM approach used in the present study allowed an estimation of effects of teacher enjoyment on student enjoyment in Grade 8, however bidirectional effects within Grade 8 could not be modeled by this approach. Future studies should address potential reciprocal effects of emotion transmission between teachers and students. These studies could be designed so that teacher emotions and student emotions are measured in repeated assessments across the school year, making it possible to model change in the interaction partners' emotions as a function of their initial levels of emotion.

Second, we used a rather molar approach for assessing relationships between student and teacher enjoyment, which were both assessed in a traitlike way with regards to a year-long class. A traitlike assessment is meaningful as it captures the overall emotional tone in classrooms. Nevertheless, it cannot embrace microprocesses that likely are at work in interpersonal transmission of emotions. Studies using a more fine-grained approach addressing emotions in specific lessons could be designed to further explore links between teacher and student affect (for a study assessing day-to-day student experiences of interest during class, see Tsai, Kunter, Lüdtke, Trautwein, \& Ryan, 2008).

Third, our study focused on mathematics classrooms and included students of a restricted age range (13-15 years). We are convinced that a domain-specific approach to student emotions is necessary to account for the intraindividual variation of emotions across academic domains (Goetz et al., 2007). However, basic functional mechanisms of relationships between emotions and their antecedents, and of interpersonal transmission of emotions, should be generalizable across domains (see also Pekrun, 2006). Future research should analyze the generalizability of the present findings to other age groups (e.g., elementary school students) and to domains other than mathematics.

\section{Conclusions}

The findings of the present study indicate that teacher enjoyment and student enjoyment in mathematics classrooms are closely linked and that the effects of teacher enjoyment on student enjoyment are mediated by teachers' displayed enthusiasm. Insights into such processes underlying affective interaction between teachers and students are of crucial importance since emotionally positive classrooms are likely successful classrooms. Emotionally positive classrooms enable teachers to best fulfill their teaching responsibilities and to maintain their emotional well-being. In addition, enhancing students' pleasant emotions in the classroom should be one important goal of instruction because these emotions are important for students' learning and achievement and because they are an important educational goal in and of themselves (Pekrun, 2006; Pekrun et al., 2002b). Certainly, teachers' goals should not simply be to make students happy. However, classrooms that are characterized by enjoyment of teaching and learning likely provide optimal grounds for overcoming obstacles and promoting positive development and achievement. 


\section{References}

Aleamoni, L. M. (1999). Student rating myths versus research facts from 1924 to 1998. Journal of Personnel Evaluation in Education, 13, 153166.

Allison, P. D. (2001). Missing data. Thousands Oaks, CA: Sage.

Ashby, F. G., Isen, A. M., \& Turken, A. U. (1999). A neuropsychological theory of positive affect and its influence on cognition. Psychological Review, 106, 529-550

Babab, E. (2007). Teachers' nonverbal behaviors and its effects on students. In R. Perry \& J. C. Smart (Eds.), The scholarship of teaching and learning in higher education: An evidence-based perspective (pp. 201261). New York: Springer.

Bandura, A. (1977). Social learning theory. Englewood Cliffs, NJ: Prentice Hall.

Bavarian State Ministry of Education. (2005). Schule und Bildung in Bayern 2005: Statistische Übersichten [School and education in Bavaria: Statistical overview]. Munich, Germany: Author.

Bliese, P. D. (2000). Within-group agreement, non-independence, and reliability: Implications for data aggregation and analysis. In K. J. Klein \& S. W. Kozlowski (Eds.), Multilevel theory, research, and methods in organizations (pp. 349-381). San Francisco, CA: Jossey-Bass.

Brigham, F. J., Scruggs, T. E., \& Mastropieri, M. A. (1992). Teacher enthusiasm in learning disabilities classrooms: Effects on learning and behavior. Learning Disabilities Research \& Practice, 7, 68-73.

Brophy, J. E. (2004). Motivating students to learn (2nd ed.). Mahwah, NJ: Erlbaum.

Brophy, J., \& Good, T. L. (1986). Teacher behavior and student achievement. In M. L. Wittock (Ed.), Handbook of research on teaching (3rd ed., pp. 328-375). New York: Macmillan.

Burke, M. J., Finkelstein, L. M., \& Dusig, M. S. (1999). On average deviation indices for estimating interrater agreement. Organizational Research Methods, 2, 49-68.

Byrne, B. M. (1998). Structural equation modeling with LISREL, PRELIS, and SIMPLIS: Basic concepts, applications, and programming. Mahwah, NJ: Erlbaum.

Christophel, D. (1990). The relationships among teacher immediacy behaviors, student motivation, and learning. Communication Education, $39,323-340$

Clausen, M. (2002). Unterrichtsqualität: Eine Frage der Perspektive? [Teaching quality: A matter of perspective?]. Münster, Germany: Waxmann

Collins, M. L. (1978). Effects of enthusiasm training on preservice elementary teachers. Research in Teacher Education, 29, 53-57.

De Jong, R., \& Westerhof, K. J. (2001). The quality of student ratings of teacher behaviour. Learning Environments Research, 4, 51-85.

Ekman, P. (1982). Emotion in the human face. New York: Cambridge University Press.

Fredrickson, B. L. (2001). The role of positive emotions in positive psychology: The broaden-and-build theory of positive emotions. American Psychologist, 56, 218-226.

Frijda, N. (1986). The emotions. Cambridge, England: Cambridge University Press.

Gage, N. L., \& Berliner, D. C. (1998). Educational psychology (6th ed.). New York: Houghton Mifflin.

Gavin, M. B., \& Hofmann, D. A. (2002). Using hierarchical linear modeling to investigate the moderating influence of leadership climate. The Leadership Quarterly, 13, 15-33.

Goetz, T., Frenzel, A. C., Pekrun, R., \& Hall, N. C. (2006). The domain specificity of academic emotional experiences. Journal of Experimental Education, 75, 5-29.

Goetz, T., Frenzel, A. C., Pekrun, R., Hall, N. C., \& Lüdtke, O. (2007). Between- and within-domain relations of students' academic emotions. Journal of Educational Psychology, 99, 715-733.
Hargreaves, A. (1998). The emotional practice of teaching. Teaching and Teacher Education, 14, 835-854.

Hargreaves, A. (2000). Mixed emotions: Teachers' perceptions of their interactions with students. Teaching and Teacher Education, 16, 811826.

Harris, M., \& Rosenthal, R. (2005). No more teachers' dirty looks: Effects of teacher nonverbal behavior on student outcomes. In R. Riggio \& R. S. Feldman (Eds.), Applications of nonverbal communication (pp. 157192). Mahwah, NJ: Erlbaum.

Hidi, S., \& Renninger, K. A. (2006). The four-phase model of interest development. Educational Psychologist, 41, 111-127.

Hochschild, A. R. (1983). The managed heart: The commercialization of human feeling. Berkeley: University of California Press.

Hox, J. J. (2002). Multilevel analysis: Techniques and applications. Mahwah, NJ: Erlbaum.

Hu, L., \& Bentler, P. M. (1999). Cutoff criteria for fit indexes in covariance structure analysis: Conventional criteria versus new alternatives. Structural Equation Modeling, 6, 1-55.

Hughes, E. (2001). Deciding to leave, but staying: Teacher burnout, precursors and turnover. International Journal of Human Resource Management, 12, 288-298.

Ingersoll, R. M. (2002). The teacher shortage: A case of wrong diagnosis and wrong prescription. NASSP Bulletin, 86, 16-31.

Jackson, D. L., Teal, C. R., Raines, S. J., Nansel, T. R., Force, R. C., \& Burdsal, C. A. (1999). The dimensions of students' perceptions of teaching effectiveness. Educational and Psychological Measurement, 59, 580-596.

Johnson, J. A. (1999). Persons in situations: Distinguishing new wine from old wine in new bottles. European Journal of Personality, 13, 443-453.

Kenny, D. A., Kashy, D. A., \& Bolger, N. (1998). Data analysis in social psychology. In D. Gilbert, S. Fiske, \& G. Lindzey (Eds.), Handbook of social psychology (Vol. 1, pp. 233-265). Boston: McGraw-Hill.

Klusmann, U., Kunter, M., Trautwein, U., Lüdtke, O., \& Baumert, J. (2008). Teachers' occupational well-being and the quality of instruction: The important role of self-regulatory patterns. Journal of Educational Psychology, 100, 702-715.

Kunter, M., Tsai, Y.-M., Klusmann, U., Brunner, M., Krauss, S., \& Baumert, J. (2008). Students' and mathematics teachers' perceptions of teacher enthusiasm and instruction. Learning and Instruction, 18, 468482.

LeBreton, J. M., \& Senter, J. L. (2008). Answers to 20 questions about interrater reliability and interrater agreement. Organizational Research Methods, 11, 815-852.

Lüdtke, O., Trautwein, U., Kunter, M., \& Baumert, J. (2006). Reliability and agreement of student ratings of the classroom environment-A reanalysis of TIMSS data. Learning Environments Research, 9, 215230 .

MacKinnon, D. P., Fairchild, A. J., \& Fritz, M. S. (2007). Mediation analysis. Annual Review of Psychology, 58, 593-614.

Marsh, H. W. (1982). SEEQ: A reliable, valid, and useful instrument for collecting students' evaluations of university teaching. British Journal of Educational Psychology, 77-95.

Marsh, H. W., Balla, J. R., \& McDonald, R. P. (1988). Goodness-of-fit indexes in confirmatory factor analysis: The effect of sample size. Psychological Bulletin, 103, 391-410.

McKinney, C. W., Robertson, C. W., Gilmore, A. C., Ford, M. J., \& Larkins, A. G. (1984). Some effects of three levels of teacher enthusiasm on student achievement and evaluation of teacher effectiveness. Journal of Instructional Psychology, 11, 119-124.

Mehta, P. D., \& Neale, M. C. (2005). People are variables too: Multilevel structural equations modeling. Psychological Methods, 10, 259-284.

Murray, H. (1983). Low-inference classroom teaching behaviors and students' ratings of college teaching effectiveness. Journal of Educational Psychology, 75, 138-149. 
Muthén, L. K., \& Muthén, B. O. (1998-2006). Mplus user's guide (4th ed.) [Computer software and manual]. Los Angeles, CA: Author.

Patrick, B. C., Hisley, J., Kempler, T., \& College, G. (2000). "What's everybody so excited about?": The effects of teacher enthusiasm on student intrinsic motivation and vitality. Journal of Experimental Education, 68, 1521-1558.

Pekrun, R. (2000). A social-cognitive, control-value theory of achievement emotions. In J. Heckhausen (Ed.), Motivational psychology of human development (pp. 143-163). Oxford, England: Elsevier.

Pekrun, R. (2006). The control-value theory of achievement emotions: Assumptions, corollaries, and implications for educational research and practice. Educational Psychology Review, 18, 315-341.

Pekrun, R., Goetz, T., \& Frenzel, A. C. (2005). Achievement Emotions Questionnaire-Mathematics (AEQ-M): User's manual. Unpublished manual, University of Munich, Department of Psychology.

Pekrun, R., Goetz, T., Titz, W., \& Perry, R. P. (2002a). Academic emotions in students' self-regulated learning and achievement: A program of qualitative and quantitative research. Educational Psychologist, 37, 91105 .

Pekrun, R., Goetz, T., Titz, W., \& Perry, R. P. (2002b). Positive emotions in education. In E. Frydenberg (Ed.), Beyond coping: Meeting goals, visions, and challenges (pp. 149-173). Oxford, England: Oxford University Press.

Pekrun, R., vom Hofe, R., Blum, W., Frenzel, A. C., Goetz, T., \& Wartha, S. (2007). Development of mathematical competencies in adolescence: The PALMA longitudinal study. In M. Prenzel (Ed.), Studies on the educational quality of schools: The final report on the DFG Priority Programme (pp. 17-37). Münster, Germany: Waxmann.

Pelletier, L. G., \& Vallerand, R. J. (1996). Supervisors' beliefs and subordinates' intrinsic motivation: A behavioral confirmation analysis. Journal of Personality and Social Psychology, 71, 331-340.

Podsakoff, P. M., MacKenzie, S. B., Lee, J.-Y., \& Podsakoff, N. P. (2003). Common method biases in behavioral research: A critical review of the literature and recommended remedies. Journal of Applied Psychology, 88, 879-903.

Pribyl, C., Sakamoto, M., \& Keaten, J. (2004). The relationship between nonverbal immediacy, student motivation, and perceived cognitive learning among Japanese college students. Japanese Psychological Research, 46, 73-85.

Rosenshine, B. (1970). Enthusiastic teaching: A review. School Review, $78,499-514$

Schafer, J. L., \& Graham, J. W. (2002). Missing data: Our view of the state of the art. Psychological Methods, 7, 147-177.

Scherer, K. R. (1986). Vocal affect expression: A review and a model for future research. Psychological Bulletin, 99, 143-156.

Schiefele, U. (1991). Interest, learning, and motivation. Educational Psychologist, 26, 299-323.

Schutz, P. A., \& Lanehart, S. L. (2002). Introduction: Emotions in education. Educational Psychologist, 37, 67-68.

Schutz, P. A., \& Pekrun, R. (Eds.). (2007). Emotions in education. San Diego, CA: Elsevier.

Seidel, T., \& Shavelson, R. J. (2007). Teaching effectiveness research in the past decade: The role of theory and research design in disentangling meta-analysis results. Review of Educational Research, 77, 454-499.

Shoda, Y. (1999). A unified framework for the study of behavioral con- sistency: Bridging Person $\times$ Situation interaction and the consistency paradox. European Journal of Personality, 13, 361-387.

Shuell, T. J. (2001). Learning theories and educational paradigms. In N. Smelser \& P. B. Baltes (Eds.), International encyclopedia of the social and behavioral sciences (pp. 8613-8620). Oxford, England: Elsevier.

Snijders, T. A. B., \& Bosker, R. J. (1999). Multilevel analysis: An introduction to basic and advanced multilevel modeling. London: Sage.

Stenlund, K. V. (1995). Teacher perceptions across cultures: The impact of students on teacher enthusiasm and discouragement in a cross-cultural context. Alberta Journal of Educational Research, 41, 145-161.

Sutton, R. E. (2000, April). The emotional experiences of teachers. Paper presented at the Annual Meeting of the American Educational Research Association, New Orleans.

Sutton, R. E. (2004). Emotional regulation goals and strategies of teachers. Social Psychology of Education, 7, 379-398.

Sutton, R. E., \& Wheatley, K. F. (2003). Teachers' emotions and teaching: A review of the literature and directions for future research. Educational Psychology Review, 15, 327-358.

Tett, R. T., \& Guterman, H. A. (2000). Situation trait relevance, trait expression, and cross-situational consistency: Testing a principle of trait activation. Journal of Research in Personality, 34, 397-423.

Trautwein, U., Lüdtke, O., Schnyder, I., \& Niggli, A. (2006). Predicting homework effort: Support for a domain-specific, multilevel homework model. Journal of Educational Psychology, 98, 438-456.

Tsai, Y.-M., Kunter, M., Lüdtke, O., Trautwein, U., \& Ryan, R. (2008). What makes lessons interesting? The role of situational and individual factors in three school subjects. Journal of Educational Psychology, 100, $460-472$.

Twenge, J. M., \& Baumeister, R. F. (2002). Self-control: A limited yet renewable resource. In M. F. Y. Kashima \& M. J. Platow (Eds.), Self and identity: Personal, social, and symbolic (pp. 57-70). Mahwah, NJ: Erlbaum.

Ullman, J. B. (2007). Structural equation modeling. In B. G. Tabachnick \& L. S. Fidell (Eds.), Using multivariate statistics (5th ed., pp. 676-780). Boston: Allyn \& Bacon.

Watson, D., Clark, L. A., \& Tellegen, A. (1988).). Development and validation of brief measures of positive and negative affect: The PANAS scales. Journal of Personality and Social Psychology, 54, 1063-1070.

Wayne, A. J., \& Youngs, P. (2003). Teacher characteristics and student achievement gains: A review. Review of Educational Research, 73, $89-122$.

Wild, T. C., Enzle, M. E., \& Hawkins, W. L. (1992). Effects of perceived extrinsic versus intrinsic teacher motivation on student reactions to skill acquisition. Personality and Social Psychology Bulletin, 18, 245-251.

Wild, T. C., Enzle, M. E., Nix, G., \& Deci, E. L. (1997). Perceiving others as intrinsically or extrinsically motivated: Effects on expectancy formation and task engagement. Personality and Social Psychology Bulletin, $23,837-848$.

Witcher, A. E., Onwuegbuzie, A. J., \& Minor, L. C. (2001). Characteristics of effective teachers: Perceptions of preservice teachers. Research in the Schools, 8, 45-57.

Witt, P., Wheeless, L., \& Allen, M. (2004). A meta-analytical review of the relationship between teacher immediacy and student learning. Соттиnication Monographs, 71, 184-207. 
Appendix A

Unstandardized Indicator Loadings and Residual (Error) Variances and Their Standard Errors of the Final Model (Mediation Model)

\begin{tabular}{|c|c|c|c|c|}
\hline \multirow[b]{2}{*}{ Variable } & \multicolumn{2}{|c|}{ Loading } & \multicolumn{2}{|c|}{ Error } \\
\hline & Coefficient & $S E$ & Coefficient & $S E$ \\
\hline \multicolumn{5}{|c|}{ Between-classes level } \\
\hline \multicolumn{5}{|c|}{ Teacher enjoyment Grade 8} \\
\hline Item 1 & $1.00^{\mathrm{a}}$ & 0.00 & 0.03 & 0.04 \\
\hline Item 2 & 0.90 & 0.11 & 0.23 & 0.07 \\
\hline Item 3 & 1.00 & 0.12 & 0.21 & 0.08 \\
\hline Item 4 & 0.73 & 0.09 & 0.25 & 0.06 \\
\hline Item 5 & 0.84 & 0.11 & 0.39 & 0.06 \\
\hline \multicolumn{5}{|c|}{ Student enjoyment Grade 7} \\
\hline Item 1 & $1.00^{\mathrm{a}}$ & 0.00 & 0.00 & 0.01 \\
\hline Item 2 & 1.14 & 0.10 & 0.01 & 0.01 \\
\hline Item 3 & 0.90 & 0.09 & 0.01 & 0.01 \\
\hline Item 4 & 1.21 & 0.22 & 0.03 & 0.02 \\
\hline \multicolumn{5}{|l|}{ Student enjoyment Grade 8} \\
\hline Item 1 & $1.00^{\mathrm{a}}$ & 0.00 & 0.00 & 0.01 \\
\hline Item 2 & 1.06 & 0.10 & 0.01 & 0.01 \\
\hline Item 3 & 1.00 & 0.13 & 0.00 & 0.01 \\
\hline Item 4 & 1.21 & 0.17 & $0.00^{\mathrm{b}}$ & 0.00 \\
\hline \multicolumn{5}{|c|}{ Perceived teacher enthusiasm Grade 8} \\
\hline Item 1 & $1.00^{\mathrm{a}}$ & 0.00 & $0.00^{\mathrm{b}}$ & 0.00 \\
\hline Item 2 & 0.99 & 0.08 & 0.05 & 0.01 \\
\hline Item 3 & 1.01 & 0.04 & 0.01 & 0.09 \\
\hline Item 4 & 0.81 & 0.03 & $0.00^{\mathrm{b}}$ & 0.00 \\
\hline \multicolumn{5}{|c|}{ Within-class level } \\
\hline \multicolumn{5}{|l|}{ Student enjoyment Grade 7} \\
\hline Item 1 & $1.00^{\mathrm{a}}$ & 0.00 & 0.37 & 0.02 \\
\hline Item 2 & 1.04 & 0.03 & 0.31 & 0.03 \\
\hline Item 3 & 1.03 & 0.02 & 0.41 & 0.03 \\
\hline Item 4 & 0.74 & 0.03 & 0.72 & 0.05 \\
\hline \multicolumn{5}{|c|}{ Student enjoyment Grade 8} \\
\hline Item 1 & $1.00^{\mathrm{a}}$ & 0.00 & 0.41 & 0.03 \\
\hline Item 2 & 1.05 & 0.03 & 0.34 & 0.03 \\
\hline Item 3 & 0.92 & 0.04 & 0.58 & 0.04 \\
\hline Item 4 & 0.80 & 0.03 & 0.66 & 0.04 \\
\hline \multicolumn{5}{|c|}{ Perceived teacher enthusiasm Grade 8} \\
\hline Item 1 & $1.00^{\mathrm{a}}$ & 0.00 & 0.60 & 0.05 \\
\hline Item 2 & 0.90 & 0.05 & 0.68 & 0.04 \\
\hline Item 3 & 0.97 & 0.04 & 0.60 & 0.04 \\
\hline Item 4 & 0.91 & 0.04 & 0.64 & 0.04 \\
\hline
\end{tabular}

${ }^{\mathrm{a}}$ Loading set to one to achieve model identification. ${ }^{\mathrm{b}}$ Variance constrained to zero to avoid model misspecification. 
Appendix B

Correlations Among the Manifest Variables of Model 2

\begin{tabular}{|c|c|c|c|c|c|c|c|c|c|c|c|c|c|c|c|c|c|}
\hline Variable & 1 & 2 & 3 & 4 & 5 & 6 & 7 & 8 & 9 & 10 & 11 & 12 & 13 & 14 & 15 & 16 & 17 \\
\hline 1. TE 8: Item 1 & - & & & & & & & & & & & & & & & & \\
\hline 2. TE 8: Item 2 & .76 & - & & & & & & & & & & & & & & & \\
\hline 3. TE 8: Item 3 & .80 & .79 & - & & & & & & & & & & & & & & \\
\hline 4. TE 8: Item 4 & .71 & .49 & .55 & - & & & & & & & & & & & & & \\
\hline 5. TE 8: Item 5 & .68 & .57 & .52 & .54 & - & & & & & & & & & & & & \\
\hline 6. PTE 8: Item 1 & .41 & .34 & .31 & .24 & .23 & - & .49 & .54 & .49 & .12 & .13 & .13 & .11 & .23 & .25 & .24 & .19 \\
\hline 7. PTE 8: Item 2 & .33 & .27 & .26 & .20 & .23 & .94 & - & .47 & .45 & .14 & .18 & .16 & .13 & .23 & .28 & .21 & .20 \\
\hline 8. PTE 8: Item 3 & .45 & .40 & .36 & .25 & .28 & .99 & .91 & - & .49 & .13 & .13 & .17 & .14 & .26 & .27 & .24 & .20 \\
\hline 9. PTE 8: Item 4 & .39 & .33 & .32 & .20 & .23 & .99 & .94 & .97 & - & .17 & .21 & .20 & .20 & .28 & .30 & .27 & .23 \\
\hline 10. SE 7: Item 1 & .36 & .44 & .25 & .26 & .13 & .38 & .22 & .39 & .44 & - & .73 & .71 & .53 & .46 & .43 & .35 & .32 \\
\hline 11. SE 7: Item 2 & .42 & .44 & .32 & .35 & .25 & .39 & .25 & .36 & .46 & .95 & - & .73 & .57 & .43 & .44 & .35 & .33 \\
\hline 12. SE 7: Item 3 & .38 & .45 & .25 & .23 & .25 & .48 & .36 & .48 & .55 & .94 & .92 & - & .52 & .44 & .43 & .39 & .32 \\
\hline 13. SE 7: Item 4 & .39 & .41 & .33 & .24 & .18 & .30 & .18 & .31 & .35 & .81 & .80 & .79 & - & .37 & .39 & .32 & .35 \\
\hline 14. SE 8: Item 1 & .58 & .55 & .43 & .30 & .20 & .65 & .57 & .64 & .68 & .74 & .74 & .72 & .63 & - & .70 & .59 & .56 \\
\hline 15. SE 8: Item 2 & .50 & .49 & .37 & .25 & .16 & .70 & .59 & .65 & .74 & .80 & .84 & .80 & .65 & .95 & - & .64 & .56 \\
\hline 16. SE 8: Item 3 & .70 & .58 & .49 & .35 & .40 & .77 & .67 & .78 & .79 & .61 & .63 & .67 & .59 & .92 & .87 & - & .51 \\
\hline 17. SE 8: Item 4 & .62 & .55 & .51 & .30 & .23 & .57 & .43 & .58 & .60 & .75 & .75 & .75 & .85 & .89 & .85 & .90 & - \\
\hline
\end{tabular}

Note. Class-level correlations are below the diagonal, and individual-level correlations are above the diagonal. TE $=$ teacher enjoyment; PTE $=$ perceived teacher enthusiasm; $\mathrm{SE}=$ student enjoyment; $7=$ Grade $7 ; 8=$ Grade 8 .

Received October 4, 2007

Revision received October 20, 2008

Accepted November 3, 2008

\section{Correction to Lee et al. (2009)}

In the article "The Contributions of Working Memory and Executive Functioning to Problem Representation and Solution Generation in Algebraic Word Problems," by Kerry Lee, Ee Lynn Ng, and Swee Fong Ng (Journal of Education Psychology, 2009, Vol. 101, No. 2, pp. 373-387), the URL published for the supplemental material was incorrect. The correct URL is http://dx.doi.org/10.1037/a0013843.supp

DOI: $10.1037 / \mathrm{a} 0016095$ 